\title{
Estimating minimum and maximum air temperature using MODIS data over Indo-Gangetic Plain
}

\author{
D B ShaH ${ }^{1, *}$, M R PANDYA ${ }^{2}, \mathrm{H} \mathrm{J}_{\text {TRIVEdi }}^{3}$ and A R JANI ${ }^{1}$ \\ ${ }^{1}$ Department of Physics, Sardar Patel University, Vallabh Vidyanagar 388 120, India. \\ ${ }^{2}$ Space Applications Centre, Indian Space Research Organization, Ahmedabad 380 015, India. \\ ${ }^{3}$ N V Patel College of Pure and Applied Sciences, Vallabh Vidyanagar 388 120, India. \\ ${ }^{*}$ Corresponding author.e-mail: dhirajshah123@gmail.com
}

Spatially distributed air temperature data are required for climatological, hydrological and environmental studies. However, high spatial distribution patterns of air temperature are not available from meteorological stations due to its sparse network. The objective of this study was to estimate high spatial resolution minimum air temperature $\left(T_{\min }\right)$ and maximum air temperature $\left(T_{\max }\right)$ over the Indo-Gangetic Plain using Moderate Resolution Imaging Spectroradiometer (MODIS) data and India Meteorological Department (IMD) ground station data. $T_{\min }$ was estimated by establishing an empirical relationship between IMD $T_{\min }$ and night-time MODIS Land Surface Temperature $\left(T_{\mathrm{s}}\right)$. While, $T_{\max }$ was estimated using the Temperature-Vegetation Index (TVX) approach. The TVX approach is based on the linear relationship between $T_{\mathrm{s}}$ and Normalized Difference Vegetation Index (NDVI) data where $T_{\max }$ is estimated by extrapolating the NDVI- $T_{\mathrm{s}}$ regression line to maximum value of $\mathrm{NDVI}_{\max }$ for effective full vegetation cover. The present study also proposed a methodology to estimate NDVI max $_{\text {using IMD mea- }}$ sured $T_{\max }$ for the Indo-Gangetic Plain. Comparison of MODIS estimated $T_{\min }$ with IMD measured $T_{\min }$ showed mean absolute error (MAE) of $1.73^{\circ} \mathrm{C}$ and a root mean square error (RMSE) of $2.2^{\circ} \mathrm{C}$. Analysis in the study for $T_{\max }$ estimation showed that calibrated $\mathrm{NDVI}_{\max }$ performed well, with the MAE of $1.79^{\circ} \mathrm{C}$ and $\mathrm{RMSE}$ of $2.16^{\circ} \mathrm{C}$.

\section{Introduction}

Air temperature is a useful environmental variable in a wide range of applications in areas of ecology, hydrology and atmospheric sciences. Land surface process models such as soil-vegetation-atmosphere transfer models (Olioso et al. 1999), distributed hydrological models (Stisen et al. 2008) and global primary production models (Prince et al. 1998) require air temperature as driving variable. Meteorological stations measure air temperature at twometer height above ground. However, density of the meteorological station network is generally sparse and installation and running cost of additional meteorological stations are very high. As a result, obtaining high spatial resolution $T_{\min }$ and $T_{\max }$ map from meteorological stations data is not possible (Willmott et al. 1991; Vogt et al. 1997). Satellite provides synoptic spatial coverage compared to discrete spatial distribution of meteorological stations, thus attracting researchers to make use of satellite data to fill in the gaps inherent in meteorological station data.

The types of methods commonly used to estimate air temperature from the $T_{\mathrm{s}}$ can be classified into five groups:

1) Statistical approaches (Davis and Tarpley 1983; Vancutsem et al. 2010) generally based on regression model, which establish the relationship

Keywords. Air temperature; land surface temperature; normalized difference vegetation index; MODIS. 
between $T_{\mathrm{s}}$ and air temperature. This method generally executes well within the region (Stisen et al. 2007).

2) Empirical solar zenith angle approach (Cresswell et al. 1999) which is also known as advanced statistical approach. Along with $T_{\mathrm{s}}$ and air temperature, it requires solar zenith angle as proxy for solar energy reaching the earth's surface. This approach basically performs individual regression analysis for each acquisition time during the day due to the changing interaction between surface and air temperature.

3) Energy balance approaches (Sun et al. 2005) that are developed from physically based processes. The major drawback of these approaches is that they require large amount of inputs that cannot be often obtained by remotely sensed observation from satellite-based platform.

4) TVX approach (Nemani and Running 1989; Goward et al. 1994; Prihodko and Goward 1997) is based on negative correlation between $T_{\mathrm{s}}$ and NDVI. This approach is contextual in nature and assumes uniform atmospheric forcing and moisture condition within the contextual array.

5) Neural network approach (Jang et al. 2004) comparatively new and promising for deriving air temperature. However, this method is empirical in nature and hard to generalize over different regions.

Generally during night time, $T_{\min }$ estimation is simpler because of the lack of solar radiation effect on thermal infrared signal and as a result there exists a linear relationship between night time $T_{\mathrm{s}}$ and $T_{\min }$. During day time, estimation of $T_{\max }$ is not simpler as difference between $T_{\mathrm{s}}$ and $T_{\max }$ is mainly controlled by the surface energy balance (Oke 1987; Zaksek and Schroedter-Homscheidt 2009). These energy balance approaches require input parameters like incoming solar radiation, cloud-cover, wind speed, soil moisture and surface roughness which are not easily available from satellite-based platform at regular interval (Prince et al. 1998). Previous studies (Florio et al. 2004; Nieto et al. 2010) have attempted to derive $T_{\max }$ using the correlation between $T_{\mathrm{s}}$ and NDVI measurements called the Temperature-Vegetation Index (TVX) approach. This method assumes that the temperature of a full cover canopy approaches the temperature of air within the canopy (Prince 1990; Czajkowski et al. 1997; Prihodko and Goward 1997). Vegetation canopies consist primarily of air filled with relatively small, thin leaves and branches that are mutually shading and the small dimensions of tile leaves in a canopy make them strong heat radiators and cause them to remain close to the ambient air temperature (Prihodko and Goward 1997). In this study, we attempt to estimate the $T_{\mathrm{s}}$ of an infinitely thick canopy for each contextual array and this is done by extrapolating the observed TVX relation to maximum vegetation cover canopy $\left(\mathrm{NDVI}_{\max }\right)$. As applicability of TVX approach requires testing over different parts of earth's surfaces, we need to better understand the potential applicability, limitation, sources of differences and biases between the meteorological stations and remotely sensed estimates, and how these differences manifest as a function of spatial and temporal scale for the TVX approach over the various parts of globe. In an earlier study, Shah et al. (2012) demonstrated retrieval of $T_{\min }$ and $T_{\max }$ over Gujarat region using MODIS products and Indian Space Research Organization (ISRO) Automatic Weather Stations (AWS) air temperature data for the year 2011. This study successfully retrieved the air temperature with mean absolute error (MAE) ranging from $1.49^{\circ}$ to $1.96^{\circ} \mathrm{C}$ and root mean square error (RMSE) ranging from $1.95^{\circ}$ to $2.46^{\circ} \mathrm{C}$. However, that study (Shah et al. 2012) provided analysis on discrete points representing the AWS stations and did not provide the spatial maps of $T_{\min }$ and $T_{\max }$ over the study area of Gujarat. Applying TVX approach on the satellite images to obtain the spatial maps is a challenging task because of the difficulty in estimating regression coefficients of TVX approach through a moving window algorithm. So there is a need to demonstrate the applicability of TVX approach on the satellite images, which is one of the major aims of the present study. A good attempt was made by Bhowmick et al. (2008) for India to estimate air temperature using K1-VHRR satellite diurnal brightness temperature (BT) and IMD as well as AWS ground observations. However, the drawback of Bhowmick et al. (2008) study was, they used the BT instead of $T_{\mathrm{s}}$ and BT changes with the active constituents of the atmosphere and many times it does not represent $T_{\mathrm{s}}$.

A study was carried out with an objective to estimate $T_{\min }$ by regression and $T_{\max }$ with TVX approach using MODIS data over the IndoGangetic Plain. Specifically, we first investigated $T_{\min }$ using night time MODIS $T_{\mathrm{s}}$ data and validated the accuracy of the retrieval. Then, during day time we employed the TVX approach to retrieve $T_{\max }$ from MODIS $T_{\mathrm{s}}$ and NDVI data. Moreover, the study also proposed to estimate the best values of $\mathrm{NDVI}_{\max }$ based on IMD measured $T_{\max }$ observation for the study region to improve the accuracy.

\section{Study area}

The study was carried out over Indo-Gangetic Plain (IGP) located in the northern part of India 
(figure 1). It encompasses about $488,000 \mathrm{~km}^{2}$ geographical area. It includes the state of Punjab, Haryana, Delhi, Chandigarh, West Bengal, Uttar Pradesh, Bihar and some parts of Rajasthan. The region has three seasons: winter (November to February), summer (March to June) and monsoon (July to October). During the clear sky days this region has the annual range of $T_{\min }$ from $2^{\circ}-30^{\circ} \mathrm{C}$ and $T_{\max }$ from $15^{\circ}-45^{\circ} \mathrm{C}$. The IGP is made up by the rivers such as Indus, Ganges, Brahmaputra and their tributaries. There is constant supply of water from the snow packed Himalayan region to these rivers and nutrient laden alluvial soil make this region very fertile for crop production and for this reason, $85 \%$ of the total area is cropland. The topography is plain and elevation of different IMD stations ranges from 6 to $347 \mathrm{~m}$ above sea level.

\section{Data and methodology}

\subsection{Meteorological station data}

Air temperature observations during 2008-2010 over the IGP were obtained from the IMD ground station measurement at $2 \mathrm{~m}$ above ground. This data included daily $T_{\min }$ and $T_{\max }$ observations. There are 19 stations located across the study area. The spatial distribution of different IMD stations is shown in figure 1. The name of IMD stations, location, elevation, and land cover type are listed in table 1 . Out of 19 IMD stations, 14 stations are located in cropland and 5 stations are positioned in urban environment.

\subsection{MODIS data}

The MODIS $T_{\mathrm{s}}$ is derived from two thermal infrared (TIR) bands; $31(10.78-11.28 \mu \mathrm{m})$ and $32(11.77-12.27 \mu \mathrm{m})$ using a split window algorithm (Wan and Dozier 1996) that corrects for atmospheric and emissivity effects using a look-up table based on global land surface emissivity in the thermal infrared bands. In this study, MODIS 8day composite (MYD11A2) $T_{\mathrm{s}}$ data for the period of 2008 to 2010 over IGP was used covering the four tiles, h24v05, h24v06, h25v05 and h25v06. The rationale behind selecting 8 -day data is that

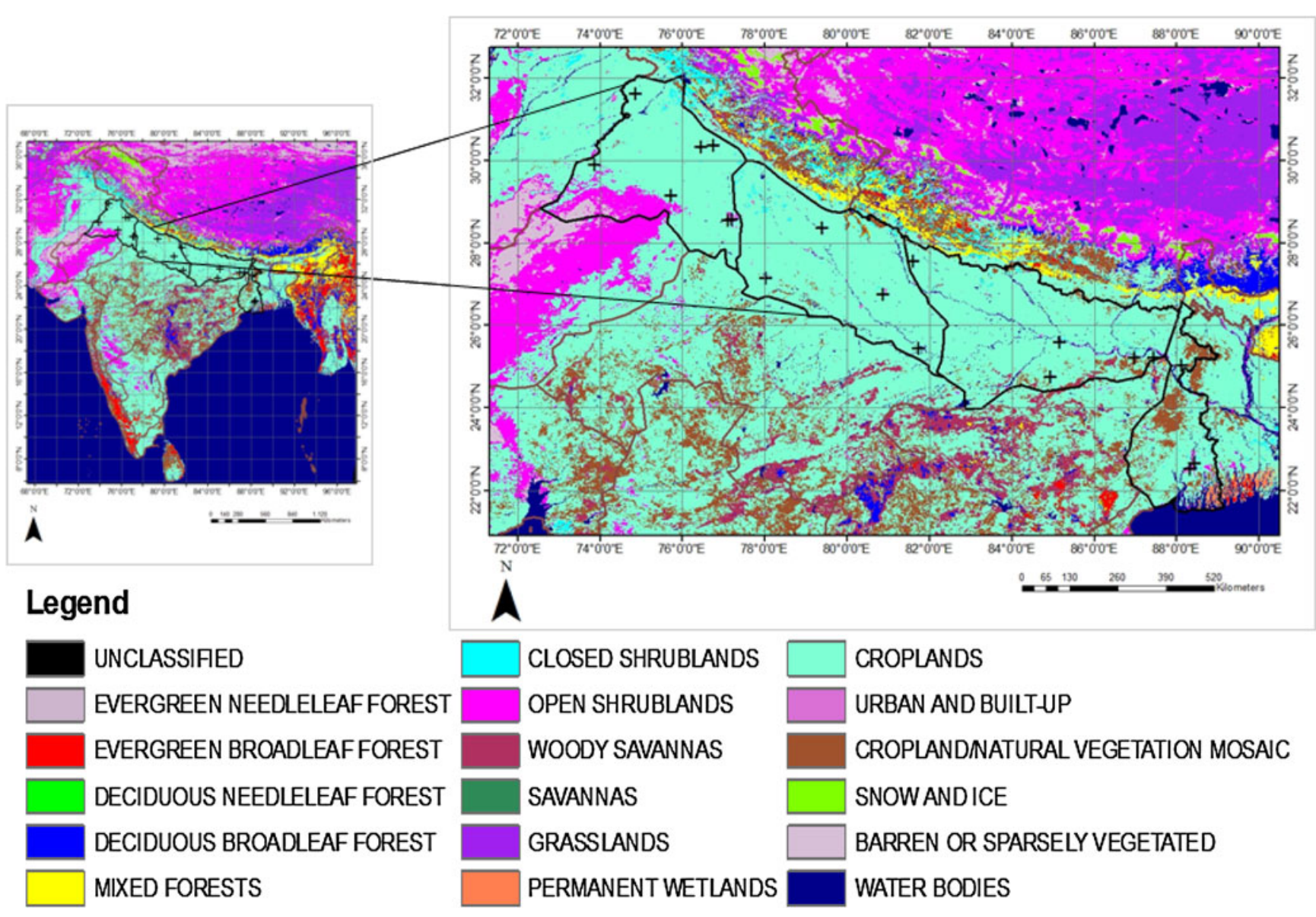

Figure 1. The study area Indo-Gangetic Plain is shown in the above figure with the location of IMD meteorological stations $(+)$, are marked along with the different Agro Climatic Zones boundary (black) and MODIS land cover type (IGBP). 
Table 1. IMD station name, latitude, longitude, land cover, and altitude for 19 IMD stations used in the study.

\begin{tabular}{|c|c|c|c|c|}
\hline IMD station & Latitude (DD) & Longitude (DD) & Altitude (m) & Land cover \\
\hline Agra & 27.16 & 78.03 & 169 & Cropland \\
\hline Allahabad & 25.45 & 81.73 & 98 & Cropland \\
\hline Bahirich & 27.56 & 81.60 & 124 & Cropland \\
\hline Bareily & 28.36 & 79.40 & 172 & Cropland \\
\hline Bhagalpur & 25.23 & 86.98 & 49 & Cropland \\
\hline Chandigarh & 30.73 & 76.88 & 347 & Cropland \\
\hline Delhi PLM & 28.56 & 77.11 & 233 & Cropland \\
\hline Gaya & 24.75 & 84.95 & 118 & Cropland \\
\hline Kolkata-Dumdum & 22.65 & 88.45 & 6 & Cropland \\
\hline Lucknow & 26.75 & 80.88 & 128 & Cropland \\
\hline Malda & 25.03 & 88.13 & 31 & Cropland \\
\hline Patiala & 30.33 & 76.46 & 251 & Cropland \\
\hline Patna & 25.60 & 85.16 & 57 & Cropland \\
\hline Purnia & 25.23 & 87.45 & 38 & Cropland \\
\hline Ambala & 30.38 & 76.76 & 272 & Urban \\
\hline Amritsar & 31.63 & 74.86 & 234 & Urban \\
\hline Delhi SFD & 28.58 & 77.20 & 216 & Urban \\
\hline Hissar & 29.16 & 75.73 & 221 & Urban \\
\hline Kolkata-Alipur & 22.53 & 88.33 & 6 & Urban \\
\hline
\end{tabular}

they are mostly filled (no data gaps except persistent cloud cover) and get average behaviour of those 8-day which reduces the efforts while working with large amount of data and still provides similar results. These MODIS data were downloaded from Level 1 and Atmosphere Archive and Distribution System (LAADS) webdata archive centre (http://ladsweb.nascom.nasa.gov). The spatial resolution of MODIS 8-day $T_{\mathrm{s}}$ data is $0.93 \mathrm{~km}$. Validation studies for MODIS $T_{\mathrm{s}}$ have shown that the accuracy is less than $1 \mathrm{~K}$ under clear-sky conditions and higher errors may occur at large view angles and in semiarid regions (Wan and $\mathrm{Li}$ 2008). The nominal equatorial passing time of Terra is around 10:30 am and pm while Aqua passes the earth's equator around 01:30 am and pm. The overpasses of the Aqua satellite are closer to the time of $T_{\text {min }}$ and $T_{\max }$ (Shah et al. 2012), thus this work made use of only MODIS Aqua data. MODIS Aqua 16day composite NDVI product (MYD013A2) was also used along with MODIS Aqua 8-day composite $T_{\mathrm{s}}$ (MYD11A2) data to estimate $T_{\max }$ using TVX approach. In order to match the compositing period of NDVI with the $T_{\mathrm{s}}$ for use in the TVX approach, two consecutive 16-day NDVI data was averaged in order to get 8-day data considering that NDVI does not change significantly within 16-day period.

\subsection{Method for minimum air temperature}

There is a significant linear correlation between $T_{\min }$ and night $T_{\mathrm{s}}$, which is the physical basis for the empirical models of $T_{\min }$ estimation (Shah et al.
2012). So for $T_{\min }$ estimation, MODIS Aqua 8-day composite night $T_{\mathrm{s}}$ products were compared with IMD $T_{\min }$ observations of 19 stations. In order to achieve this relationship, following procedure was carried out:

- The IMD $T_{\min }$ data was aggregated to 8-day period by averaging the daily observations,

- For each station MODIS $T_{\mathrm{s}}$ values were extracted for a small window of $3 \times 3$ pixels around the nearest points of IMD ground stations,

- The mean value of all pixels within the window was then used for comparison with IMD $T_{\min }$ of the same 8-day compositing period,

- The observations from the year 2008 and 2009 used for correlation analysis and model calibration and the remaining year 2010 observations were used to validate the model,

- The linear regression analysis was carried out between MODIS $T_{\mathrm{s}}$ and IMD $T_{\min }$, and

- A cross validation was performed by predicting $T_{\min }$ for each station and analyzing the statistics including the bias (B), the mean absolute error (MAE), the root mean square error (RMSE) and the coefficient of determination $\left(R^{2}\right)$, for the year 2010.

\subsection{Method for maximum air temperature}

The basic consideration of TVX approach for air temperature estimation is the surface temperatures of a dense and thick vegetation cover, measured by a thermal sensor, is very close to the ambient air temperature (Goward et al. 1985). Such a dense 
vegetation cover is described by maximum NDVI $\left(\mathrm{NDVI}_{\max }\right)$. Further, during daytime observations, a strong, negative correlation is typically found between surface temperatures and NDVI in local spatial arrays of observations (Prihodko and Goward 1997). Example is presented in figure 2 for MODIS Aqua $T_{\mathrm{s}}$-NDVI correlation for $9 \times 9$ pixel window around Delhi PLM IMD station. A linear regression for these pixels within the window was used for generation of slope $(\alpha)$ and intercept $(\beta)$ of the equation

$$
T_{\mathrm{s}}=\alpha \times \mathrm{NDVI}+\beta .
$$

After calculating the regression parameter $\alpha$ and $\beta$, the canopy temperature can be estimated by allowing the linear relation to intersect with the NDVI of full vegetation cover $\left(\mathrm{NDVI}_{\max }\right)$ which is equal to air temperature and calculated using the following equation.

$$
T_{\mathrm{c}}=\alpha \times \mathrm{NDVI}_{\max }+\beta \approx \text { Air temperature }
$$

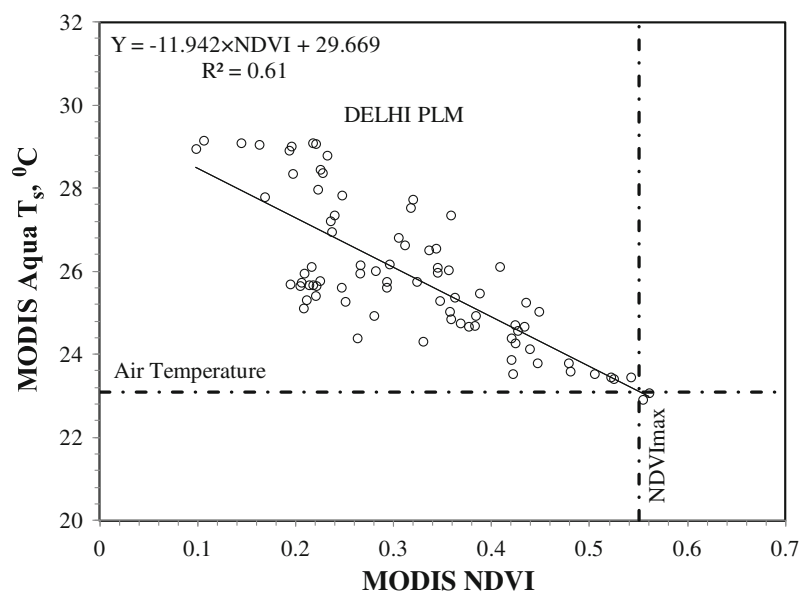

Figure 2. The basis of TVX approach is shown in the above figure, where the example of $T_{\mathrm{S}}$-NDVI correlation for a $9 \times$ 9 pixel window around the Delhi PLM field site. The $T_{\max }$ is estimated by extending the regression line to an NDVI for effective full vegetation cover.
Value of $\mathrm{NDVI}_{\max }$ is very critical but $\mathrm{NDVI}_{\max }$ varies significantly with different satellite data and study areas. Numerous values have been reported in the literature. Table 2 gives values reported in the literature for $\mathrm{NDVI}_{\max }$ over past decade over different areas of earth's surfaces.

The slope and intercept between the NDVI and $T_{\mathrm{s}}$ were computed in a $9 \times 9$ moving window. The size of this moving window act in response to a trade-off between being big enough in order to obtain a reasonable number of valid observations even if not all pixels within the contextual array can be used like in case they are identified as water (negative NDVI) or cloud (no data). This TVX approach assumes uniform atmospheric forcing and moisture condition within the contextual array because it deforms the straight line fit to the NDVI- $T_{\mathrm{s}}$ scatter plot. Further, in some cases, positive slope was observed because of heterogeneity in landscape or due to presence of residual cloud which cannot be removed by MODIS cloud mask product. Those contextual arrays must be removed because it denies the theoretical consideration of TVX approach. In the process of stationwise validation, four statistical measures B, MAE, RMSE and $R^{2}$ were also computed to assess the accuracy of the retrieved $T_{\max }$.

\section{Results and discussion}

The $T_{\min }$ and $T_{\max }$ data derived from the 19 IMD stations were compared with MODIS $T_{\mathrm{s}}$ day and night data derived from $3 \times 3$ pixel average located over stations. Figure 3 shows the temporal change for four stations located in different parts of the study region confirming that both $T_{\mathrm{s}}$ and air temperature have seasonal cycles. During night time, good temporal agreements were observed between $T_{\text {min }}$ and MODIS $T_{\mathrm{s}}$, while significant differences were found during day time depending upon the land cover type and seasonality.

\begin{tabular}{|c|c|c|c|}
\hline $\mathrm{NDVI}_{\max }$ & Satellite data used & Study area & References \\
\hline 0.7 & AVHRR & Boreas, Canada & Czajkowski et al. (1997) \\
\hline 0.86 & AVHRR & Manhattan, USA & Prihodko and Goward (1997) \\
\hline 0.77 & Landsat TM and SPOT & West Africa & Boegh et al. (1999) \\
\hline 0.65 & AVHRR & USA & Czajkowski et al. (2000) \\
\hline 0.7 & AVHRR & Red Arkansas & Lakshmi et al. (2001) \\
\hline 0.9 & AVHRR & West Africa & Goward et al. (2002) \\
\hline 0.65 & MSG SEVIRI & Senegal, West Africa & Stisen et al. (2007) \\
\hline 0.65 and 1 & MODIS & Africa & Vancutsem et al. (2010) \\
\hline 0.996 & MSG SEVIRI & Iberian Peninsula & Nieto et al. (2010) \\
\hline 0.95 & Landsat 7 ETM+ & Germany, Europe & Wloczyk et al. (2011) \\
\hline
\end{tabular}

Table 2. Numerous values reported in literature for NDVImax for TVX approach over past decade. 

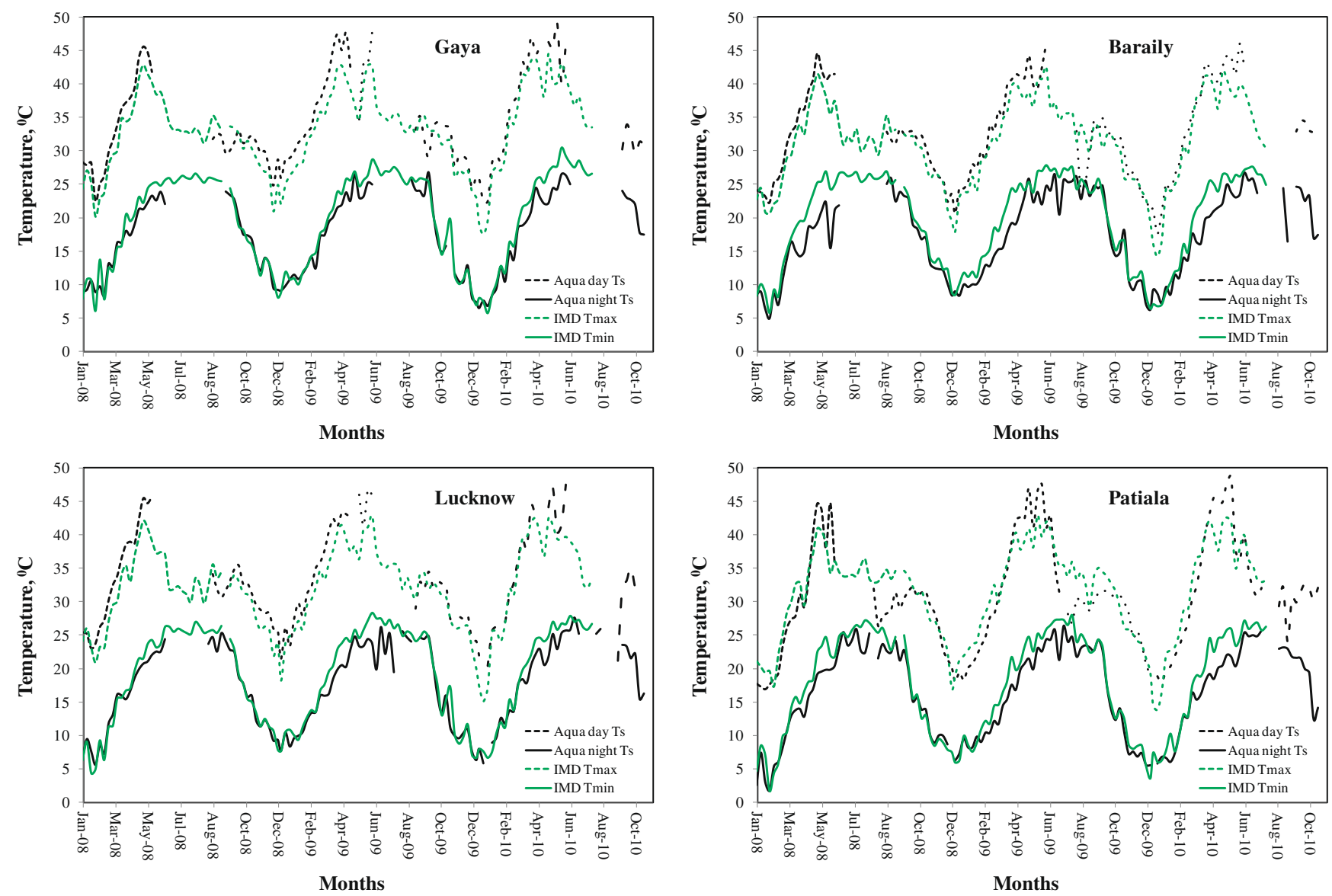

Figure 3. $T_{\min }$ and $T_{\max }$ profile derived from IMD stations (green) and MODIS Aqua day/night $T_{\mathrm{s}}$ measurements (black) for four stations over different parts of the study area.

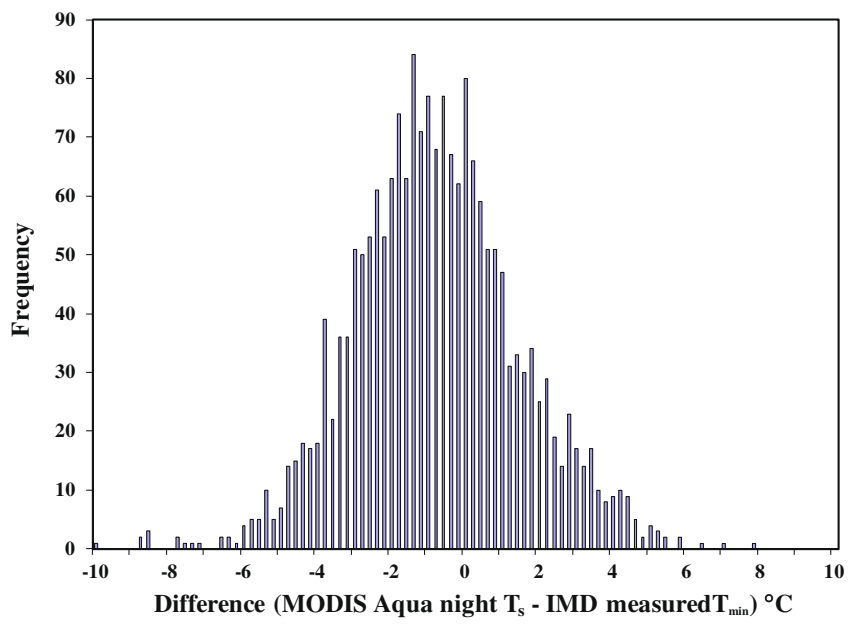

Figure 4. The frequency distribution histogram of difference between MODIS Aqua derived night $T_{\mathrm{s}}$ and IMD $T_{\min }$.

\subsection{Minimum air temperature using statistical analysis}

Night time MODIS $T_{\mathrm{s}}$ and IMD measured $T_{\min }$ differences were quantified on 8-day basis. The frequency distribution histogram of this difference is showed in figure 4. In addition, MAE, median, standard deviation, $R^{2}$, slope and intercept are presented in table 3 . The stations are also organized land cover-wise for possible relation between land cover and level of correctness.

The skewness value for the differences between night time MODIS Aqua $T_{\mathrm{s}}$ and IMD measured $T_{\min }$ is 0.07 indicating evenly distributed data as seen in histogram of figure 4 . The slope and intercept between the observed and predicted according to Pineiro et al. (2008), is that the good model always follows 1:1 line (slope is unity and no intercept). From table 3, it is clear that all the stations have slope close to unity with small intercept. A total of 1491 observations of IMD $T_{\min }$ and night time MODIS $T_{\mathrm{s}}$ obtained during the year 2008 and 2009 were used for the regression analysis and leaving the 453 observations corresponding to the year 2010 were used for validation purpose. From figure 5 , it can be seen that there is significant linear correlation exists between IMD $T_{\min }$ and night time MODIS Aqua $T_{\mathrm{s}}$. Further, the $R^{2}$ was 0.90 with the RMSE of $2.20^{\circ} \mathrm{C}$ indicating a good correlation. Analysis performed between MODIS Aqua night $T_{\mathrm{s}}$ and IMD $T_{\min }$ showed good accuracy for 
Table 3. Mean absolute error (MAE), median (MED), standard deviation (SD), coefficient of determination ( $\left.R^{2}\right)$, slope and intercept computed between night MODIS $T_{s}$ and IMD $T_{\min }$.

\begin{tabular}{|c|c|c|c|c|c|c|c|}
\hline Station & Land cover & MAE & MED & $\mathrm{SD}$ & $R^{2}$ & Slope & Intercept \\
\hline Agra & Cropland & 2.05 & 0.80 & 2.37 & 0.93 & 1.22 & -5.13 \\
\hline Allahabad & Cropland & 2.83 & -2.50 & 1.73 & 0.94 & 1.05 & 1.85 \\
\hline Bahirich & Cropland & 1.33 & -0.77 & 1.45 & 0.96 & 1.09 & -0.53 \\
\hline Baraily & Cropland & 2.25 & -1.68 & 1.97 & 0.92 & 1.05 & 1.20 \\
\hline Bhagalpur & Cropland & 2.77 & -2.89 & 1.25 & 0.95 & 1.01 & 2.51 \\
\hline Chandigarh & Cropland & 1.90 & -1.43 & 1.89 & 0.93 & 1.06 & 0.31 \\
\hline Delhi PLM & Cropland & 1.53 & -1.24 & 1.46 & 0.97 & 1.07 & 0.02 \\
\hline Gaya & Cropland & 1.40 & -0.97 & 1.47 & 0.97 & 1.12 & -1.13 \\
\hline Kolkata-Dumdum & Cropland & 1.75 & -0.07 & 2.29 & 0.83 & 1.10 & -1.55 \\
\hline Lucknow & Cropland & 1.43 & -0.85 & 1.69 & 0.95 & 1.10 & -0.73 \\
\hline Malda & Cropland & 2.54 & -2.49 & 1.36 & 0.93 & 1.01 & 2.34 \\
\hline Patiala & Cropland & 1.76 & -1.45 & 1.65 & 0.96 & 1.09 & 0.10 \\
\hline Patna & Cropland & 2.09 & 1.75 & 1.90 & 0.95 & 1.23 & -6.35 \\
\hline Purnia & Cropland & 1.53 & -1.18 & 1.33 & 0.95 & 1.05 & 0.46 \\
\hline Ambala & Urban & 1.41 & 0.47 & 1.88 & 0.94 & 1.03 & -0.86 \\
\hline Amritsar & Urban & 2.41 & 2.08 & 2.06 & 0.95 & 1.10 & -3.87 \\
\hline Delhi SFD & Urban & 1.53 & -0.05 & 1.84 & 0.97 & 1.19 & -3.47 \\
\hline Hissar & Urban & 2.67 & -2.44 & 1.64 & 0.95 & 1.01 & 2.46 \\
\hline Kolkata-Alipur & Urban & 1.47 & -0.37 & 1.90 & 0.88 & 1.14 & -2.23 \\
\hline
\end{tabular}

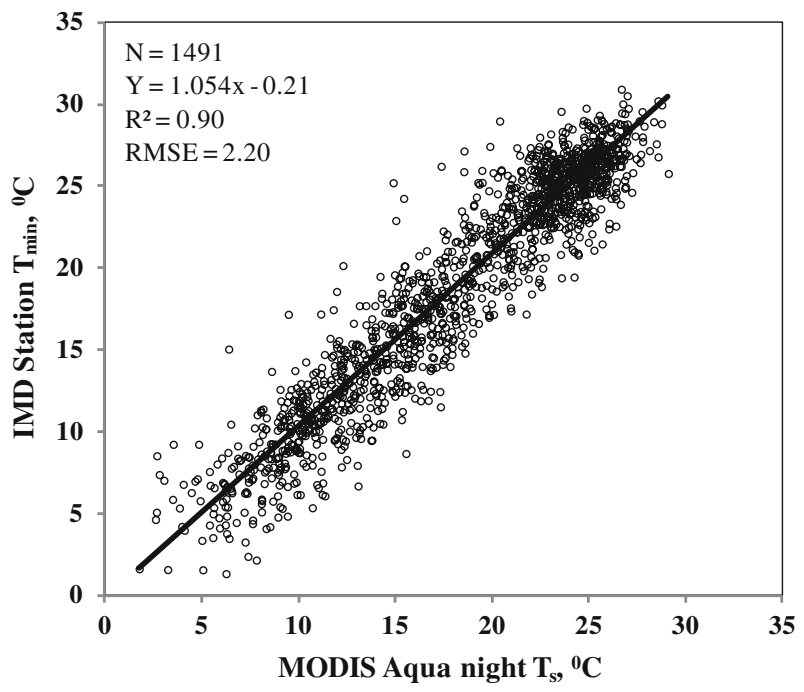

Figure 5. Scatter plot between IMD station $T_{\min }$ and MODIS derived Aqua night $T_{\mathrm{s}}$.

all the stations with the MAE of $1.33^{\circ}-2.83^{\circ} \mathrm{C}$, median of $-2.89^{\circ}$ to $2.04^{\circ} \mathrm{C}$ and standard deviation (SD) of $1.25^{\circ}-2.37^{\circ} \mathrm{C}$ (table 3$)$. Statistical analysis was performed between MODIS estimated and IMD measured $T_{\min }$ for each station for the year 2010 (table 4). It showed good performance for all the stations with the bias of $-0.11^{\circ}$ to $0.11^{\circ} \mathrm{C}$, MAE of $1.09^{\circ}-2.54^{\circ} \mathrm{C}$, RMSE $1.28^{\circ}-2.85^{\circ} \mathrm{C}$ and $R^{2}$ of $0.90-0.99$. Accuracy was also estimated by calculating the residual error for the observations using MODIS Aqua (figure 6), $83 \%$ of estimated $T_{\min }$ is within $3^{\circ} \mathrm{C}$ and $97 \%$ of the estimated $T_{\min }$ is within
Table 4. Statistical analysis between MODIS predicted and IMD observed $T_{\text {min }}$ observations for each station.

\begin{tabular}{lrccc}
\hline Station & Bias & MAE & RMSE & $R^{2}$ \\
\hline Agra & 0.0734 & 2.26 & 2.71 & 0.93 \\
Allahabad & -0.0991 & 2.24 & 2.71 & 0.96 \\
Bahirich & -0.0452 & 1.19 & 1.55 & 0.97 \\
Baraily & -0.0659 & 1.82 & 2.29 & 0.94 \\
Bhagalpur & -0.1135 & 2.55 & 2.85 & 0.96 \\
Chandigarh & -0.0547 & 1.45 & 1.88 & 0.96 \\
Delhi PLM & -0.0669 & 1.65 & 2.02 & 0.97 \\
Gaya & -0.0545 & 1.33 & 1.61 & 0.98 \\
Kolkata-Dumdum & -0.0004 & 1.79 & 1.99 & 0.90 \\
Lucknow & -0.0238 & 1.09 & 1.28 & 0.97 \\
Malda & -0.0849 & 1.81 & 2.22 & 0.95 \\
Patiala & -0.0763 & 1.68 & 2.19 & 0.95 \\
Patna & 0.1151 & 2.28 & 2.78 & 0.96 \\
Purnia & -0.0506 & 1.20 & 1.62 & 0.96 \\
Ambala & 0.0590 & 1.50 & 1.86 & 0.96 \\
Amritsar & 0.0940 & 1.97 & 2.29 & 0.97 \\
Delhi SFD & -0.0108 & 1.22 & 1.47 & 0.98 \\
Hissar & -0.0893 & 2.30 & 2.82 & 0.92 \\
Kolkata-Alipur & -0.0010 & 1.64 & 1.81 & 0.92 \\
\hline
\end{tabular}

$5^{\circ} \mathrm{C}$. Hence, we found that MODIS Aqua $T_{\mathrm{s}}$ data is useful for estimating $T_{\min }$. Figure 7 presents a high-spatial resolution monthly $T_{\min }$ of IGP generated from the MODIS Aqua $T_{\mathrm{s}}$ product for the year 2010.

Relationship between land cover type and level of accuracy was investigated for detailed analysis. For majority of stations located in the cropland 
region and few stations placed in urban area, little differences were found in the level of accuracy in retrieving $T_{\min }$. However, for the stations located close to water bodies (Agra, Allahabad and Patna), the accuracy decreased in estimating $T_{\min }$. The cause may be due to differences between water and soil physical properties concerning their specific heat and density, soil take less time to warm up and cool down than water bodies. Further, water bodies increase surrounding atmospheric moisture and this induces smaller temperature amplitudes near large water bodies resulting in erroneous $T_{\min }$ estimation.

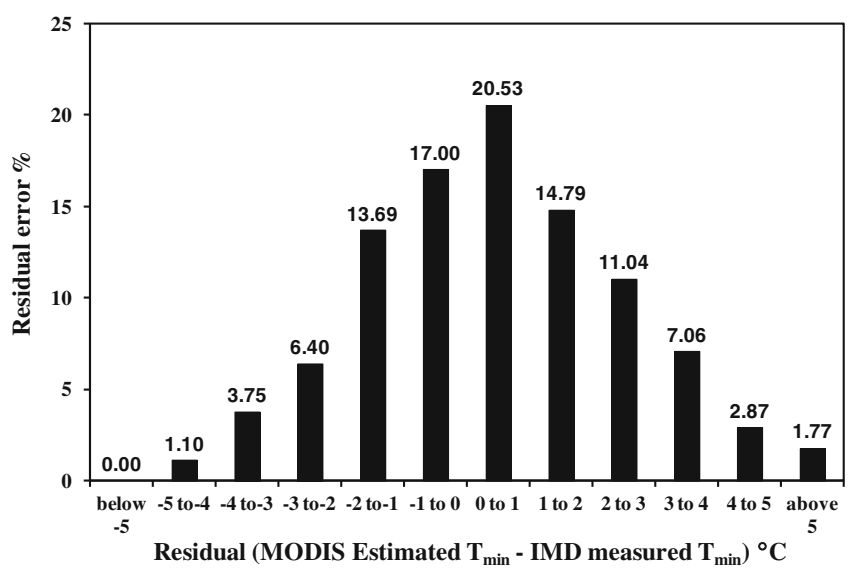

Figure 6. Histogram of residual for MODIS Aqua estimated $T_{\min }$ and IMD measured $T_{\min }$.

\subsection{Maximum air temperature using TVX approach}

Slope and intercept for NDVI- $T_{\mathrm{s}}$ contextual arrays were calculated for all the 19 stations on 8-day composite MODIS product. $T_{\max }$ was estimated by extrapolating the NDVI- $T_{\mathrm{s}}$ regression line to a maximum value of $\mathrm{NDVI}_{\max }$ for effective full vegetation cover. Here, we have selected different values of $\mathrm{NDVI}_{\max }$ ranging from 0.55 to 1 in the increment of 0.05 . This estimated $T_{\max }$ for each $\mathrm{NDVI}_{\max }$ values were then compared with the IMD measured $T_{\max }$. The results in table 5 shows the MAE calculated for MODIS estimated $T_{\max }$ and IMD measured $T_{\max }$ for different values of $\mathrm{NDVI}_{\max }$. Overall best result is obtained with $\mathrm{NDVI}_{\max }$ value 0.55. The scatter plot between MODIS derived $T_{\max }$ and IMD measured $T_{\max }$ (figure 8) showed overall strong correlation with $R^{2}$ of 0.88 and the RMSE of $2.16^{\circ} \mathrm{C}$ for $\mathrm{NDVI}_{\max }$ value 0.55 . Further, a comparison of the MODIS estimated $T_{\max }$ and IMD measured $T_{\max }$ for all observations (figure 8) showed the tendency to overestimation with decreasing $T_{\max }$. Our results showed similar performances compared to previous similar studies performed by Czajkowski et al. (1997) in Canada, with the RMSE of $4.2^{\circ} \mathrm{C}$, Prihodko and Goward (1997) in Kanas, with the RMSE of $2.9^{\circ} \mathrm{C}$ and Prince et al. (1998) did comparative study of different validation sites resulting in RMSEs of $3.48^{\circ} \mathrm{C}$
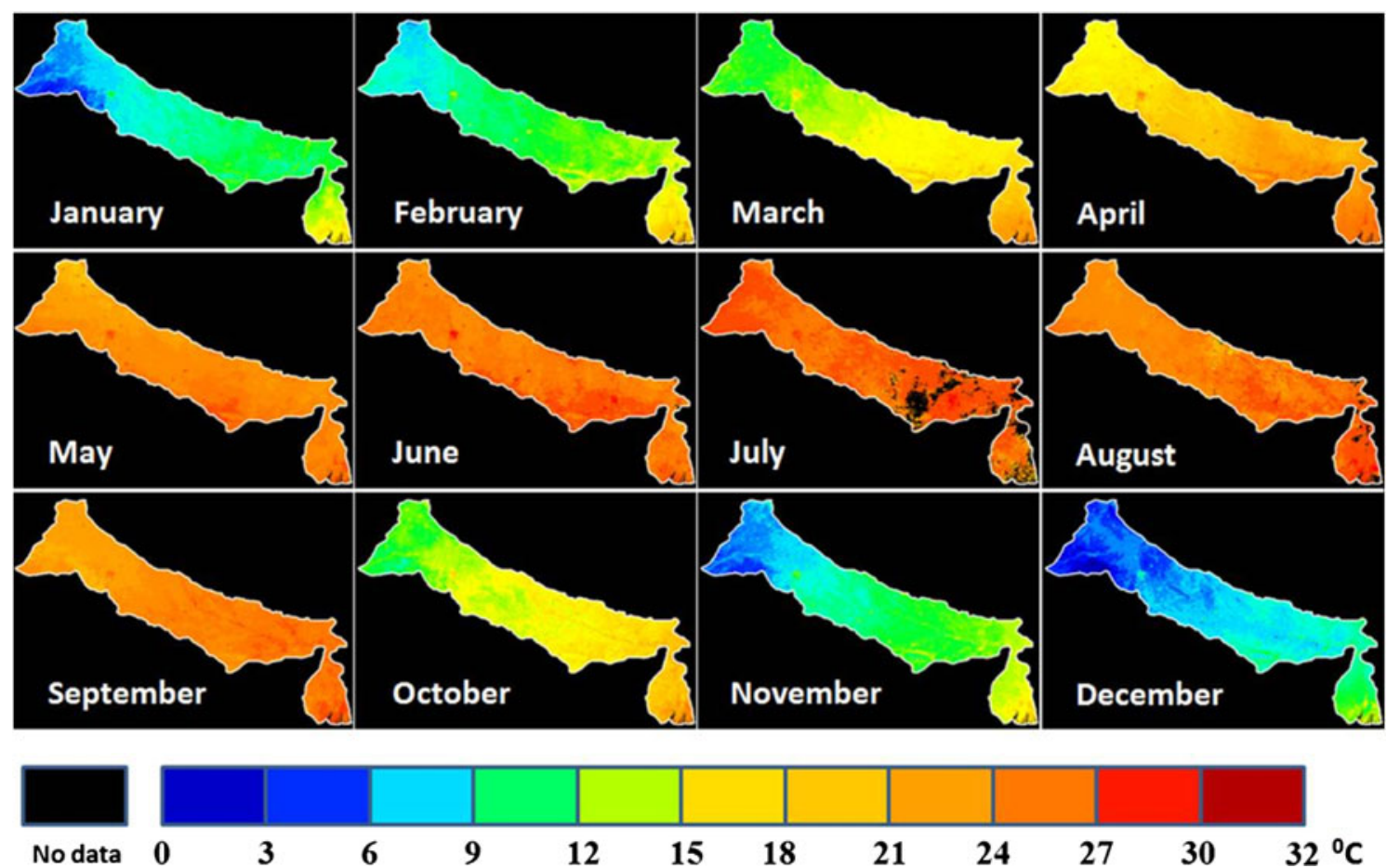

Figure 7. Spatial distribution of monthly average $T_{\min }$ images over Indo-Gangetic Plain for the year 2010. 
Table 5. Monthly reliance of MAE for different values of NDVImax calculated between TVX predicted and IMD measured Tmax values.

\begin{tabular}{lccccccccccc}
\hline & \multicolumn{10}{c}{ MAE for different values of NDVI max } \\
\cline { 2 - 11 } Months & $\mathbf{1 . 0 0}$ & $\mathbf{0 . 9 5}$ & $\mathbf{0 . 9 0}$ & $\mathbf{0 . 8 5}$ & $\mathbf{0 . 8 0}$ & $\mathbf{0 . 7 5}$ & $\mathbf{0 . 7 0}$ & $\mathbf{0 . 6 5}$ & $\mathbf{0 . 6 0}$ & $\mathbf{0 . 5 5}$ & $\mathbf{0 . 5}$ \\
\hline January & 2.69 & 2.52 & 2.36 & 2.22 & 2.11 & 2.02 & 1.97 & 1.98 & 2.03 & 2.13 & 2.26 \\
February & 3.45 & 3.02 & 2.62 & 2.24 & 1.91 & 1.62 & 1.40 & 1.23 & 1.27 & 1.39 & 1.65 \\
March & 5.81 & 5.21 & 4.62 & 4.03 & 3.46 & 2.94 & 2.48 & 2.10 & 1.83 & 1.74 & 1.82 \\
April & 6.48 & 5.87 & 5.27 & 4.68 & 4.10 & 3.53 & 3.00 & 2.52 & 2.14 & 1.86 & 1.91 \\
May & 6.62 & 6.00 & 5.40 & 4.83 & 4.27 & 3.73 & 3.23 & 2.77 & 2.46 & 2.30 & 2.41 \\
June & 5.81 & 5.28 & 4.78 & 4.29 & 3.83 & 3.39 & 2.98 & 2.67 & 2.47 & 2.36 & 2.39 \\
July & 5.26 & 4.94 & 4.63 & 4.32 & 4.02 & 3.73 & 3.46 & 3.24 & 3.08 & 2.96 & 2.91 \\
August & 6.58 & 6.04 & 5.50 & 4.96 & 4.42 & 3.89 & 3.39 & 2.97 & 2.61 & 2.34 & 2.17 \\
September & 5.27 & 4.82 & 4.37 & 3.93 & 3.51 & 3.13 & 2.77 & 2.44 & 2.12 & 1.86 & 1.98 \\
October & 3.68 & 3.31 & 2.95 & 2.59 & 2.24 & 1.90 & 1.58 & 1.33 & 1.16 & 1.08 \\
November & 2.52 & 2.26 & 2.00 & 1.77 & 1.55 & 1.36 & 1.22 & 1.14 & 1.15 & 1.22 & 1.34 \\
December & 2.06 & 1.91 & 1.76 & 1.64 & 1.54 & 1.45 & 1.39 & 1.39 & 1.46 & 1.57 & 1.74 \\
All & 4.51 & 4.09 & 3.67 & 3.27 & 2.90 & 2.55 & 2.24 & 2.00 & 1.85 & 1.79 & 1.84 \\
\hline
\end{tabular}

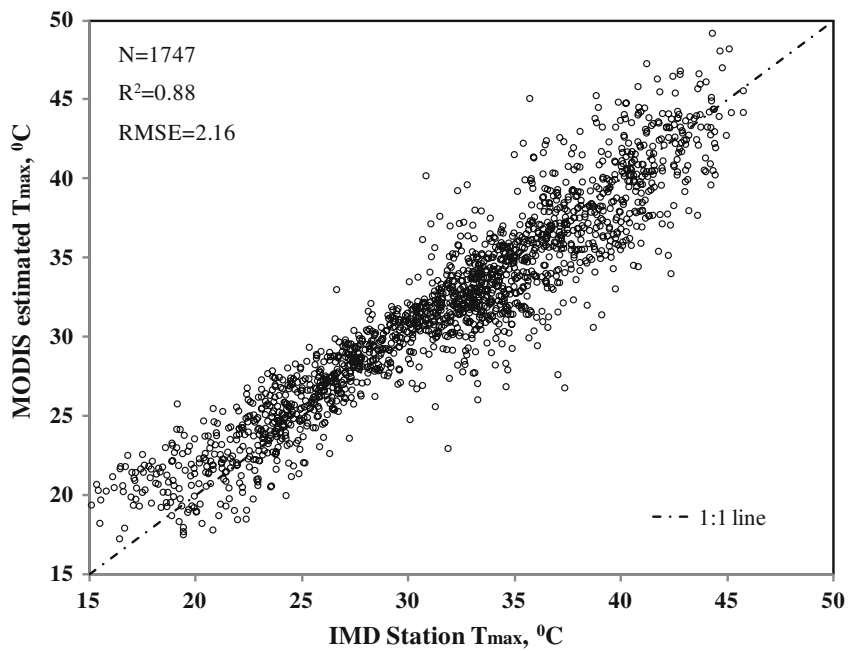

Figure 8. Scatter plot for MODIS Aqua derived $T_{\max }$ and IMD station measured $T_{\max }$.

for FIFE, $1.72^{\circ} \mathrm{C}$ in HAPEX-Sahel, $2.21^{\circ} \mathrm{C}$ over BOREAS and $4.85^{\circ} \mathrm{C}$ for the Red-Arkanas basin. This error value falls within the error of both satellite and ground measurement methods. Figure 9 showed annual dependency of MAE for the two different values of $\mathrm{NDVI}_{\max }$ (i.e., 0.55 and 0.65 ). Result confirmed that MAE was the lowest for $\mathrm{NDVI}_{\text {max }}$ value 0.65 during winter months and for rest of the months MAE was the smallest amount for $\mathrm{NDVI}_{\max }$ value of 0.55 . Table 6 demonstrates the statistical analysis between MODIS predicted and IMD observed $T_{\max }$ observations for individual station. The individual station validation generally showed good results with the correlation coefficient as given in table 6 ranging from 0.71 to 0.94 , the Bias varies from -0.0279 to $0.0527^{\circ} \mathrm{C}$, MAE ranging from 1.13 to $2.49^{\circ} \mathrm{C}$ and RMSE varies from

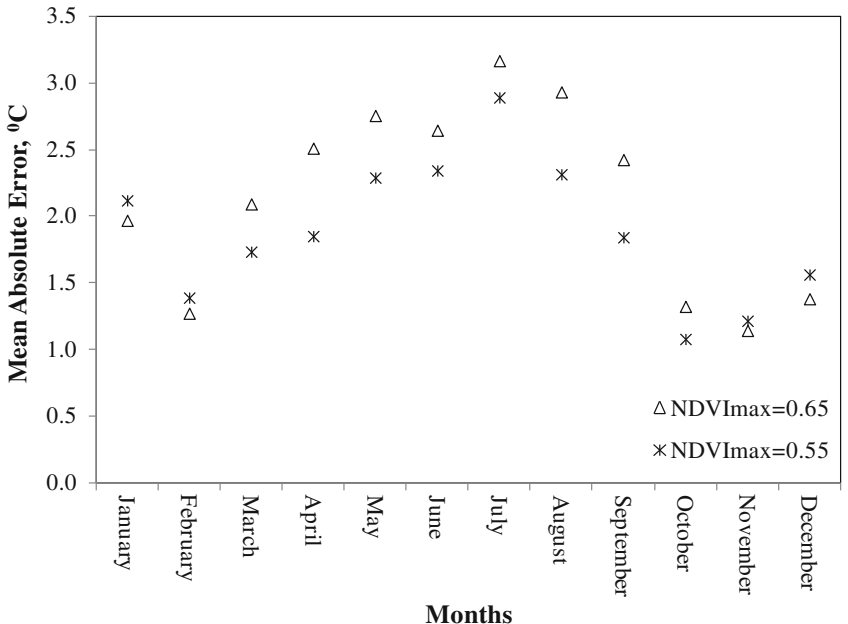

Figure 9. Annual dependency of MAE for $T_{\max }$ estimated for $\mathrm{NDVI}_{\max }=0.55$ and $\mathrm{NDVI}_{\max }=0.65$.

1.54 to $3.19^{\circ} \mathrm{C}$ found between MODIS estimated and IMD observed $T_{\max }$. Figure 10 shows the residual error between MODIS estimated $T_{\max }$ and IMD measured $T_{\max }$ for $\mathrm{NDVI}_{\max }$ value 0.55 , about $37 \%$ of all measurements had deviation smaller than $1^{\circ} \mathrm{C}, 65 \%$ smaller than $2^{\circ} \mathrm{C}, 82 \%$ smaller than $3{ }^{\circ} \mathrm{C}$, and only less than $5 \%$ measurements had deviation larger than $5^{\circ} \mathrm{C}$, which represents overall good accuracy for $T_{\max }$ estimation. The TVX approach was applied for the whole study area in a sliding window mode around center pixel to preserve the spatial resolution. Figure 11 is an example of the high-spatial resolution monthly average $T_{\max }$ estimation produced by the TVX method for the year 2010.

Figure 12 showed monthly variation of slope and intercept generated from NDVI- $T_{\mathrm{s}}$ correlation 
Table 6. Statistical analysis between MODIS predicted and IMD observed $T_{\max }$ observations for each station.

\begin{tabular}{lrrrr}
\hline Station & \multicolumn{1}{c}{ Bias } & MAE & RMSE & $R^{2}$ \\
\hline Agra & 0.0527 & 2.07 & 2.62 & 0.93 \\
Allahabad & 0.0450 & 1.45 & 2.45 & 0.92 \\
Bahirich & 0.0393 & 2.21 & 3.00 & 0.86 \\
Baraily & 0.0273 & 1.57 & 2.09 & 0.92 \\
Bhagalpur & 0.0331 & 2.07 & 2.44 & 0.93 \\
Chandigarh & 0.0010 & 1.48 & 1.98 & 0.92 \\
Delhi PLM & -0.0133 & 2.01 & 2.79 & 0.86 \\
Gaya & 0.0396 & 1.80 & 2.23 & 0.94 \\
Kolkata-Dumdum & 0.0084 & 1.13 & 1.54 & 0.90 \\
Lucknow & 0.0196 & 1.58 & 1.97 & 0.92 \\
Malda & -0.0241 & 1.63 & 2.21 & 0.81 \\
Patiala & -0.0365 & 1.95 & 2.47 & 0.90 \\
Patna & 0.0351 & 1.60 & 1.99 & 0.88 \\
Purnia & 0.0403 & 2.49 & 3.19 & 0.71 \\
Ambala & 0.0199 & 1.61 & 2.13 & 0.92 \\
Amritsar & 0.0212 & 1.83 & 2.29 & 0.93 \\
Delhi SFD & -0.0279 & 1.77 & 2.50 & 0.89 \\
Hissar & 0.0025 & 1.60 & 2.03 & 0.93 \\
Kolkata-Alipur & 0.0267 & 1.42 & 1.82 & 0.85 \\
\hline
\end{tabular}

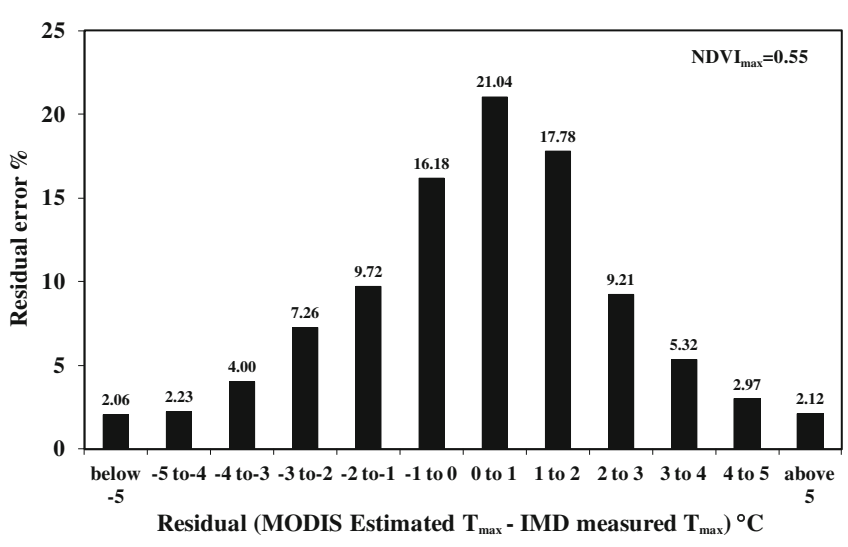

Figure 10. Histogram of residual for MODIS Aqua derived $T_{\max }$ and IMD station measured $T_{\max }$ for the $\mathrm{NDVI}_{\max }=$ 0.55 .

for contextual array. It shows highest slope (negative) and intercept was found during summer months whereas lower values during winter season. Czajkowski et al. (1997) showed that the NDVI- $T_{\mathrm{s}}$ slope decreases with high solar zenith angles and, therefore, the slope should be smaller during the winter and higher during the summer months. Further, during the month of July, there is sharp plunge, i.e., due to the presence of residual cloud that cannot be removed from MODIS cloud mask (MYD035) product which may be the reason for increase error for $T_{\max }$ estimation during the persistent cloud cover months.
For the TVX approach, possible sources of errors and limitations are:

- The largest errors occur for $T_{\max }$ estimation is during monsoon season because station measurements were averaged over cloudy as well as clear sky days while the TVX approach samples only clear sky pixels with 8-day frequency and this may contribute to a warm bias in $T_{\max }$ estimation.

- The relationship between NDVI and $T_{\mathrm{s}}$ changes according to seasons (Bayarjargal et al. 2006) and also with the surface moisture conditions. Hence, extreme heterogeneity in soil moisture within the contextual array decreases the correlation between NDVI and $T_{\mathrm{s}}$ resulting an increase in the error in estimating $T_{\max }$ (Lakshmi et al. 2001).

- Atmospheric water vapour is also an important component which traps long-wave radiation from the heated land surface. There is more water vapour in summer and like other trace greenhouse gases, water vapour has the effect to warm both the land surface and air, but the magnitude of the warming effect in terms of radiative forcing due to greenhouse gases is different for the air and the land surface (Zhang et al. 2010) and this effect of differential warming leads to erroneous estimation of $T_{\max }$.

- IGP is highly affected by fog during winter season and that introduces large error in the estimation of $T_{\mathrm{s}}$ which finally leads to increase the error for both $T_{\min }$ and $T_{\max }$ estimation. 

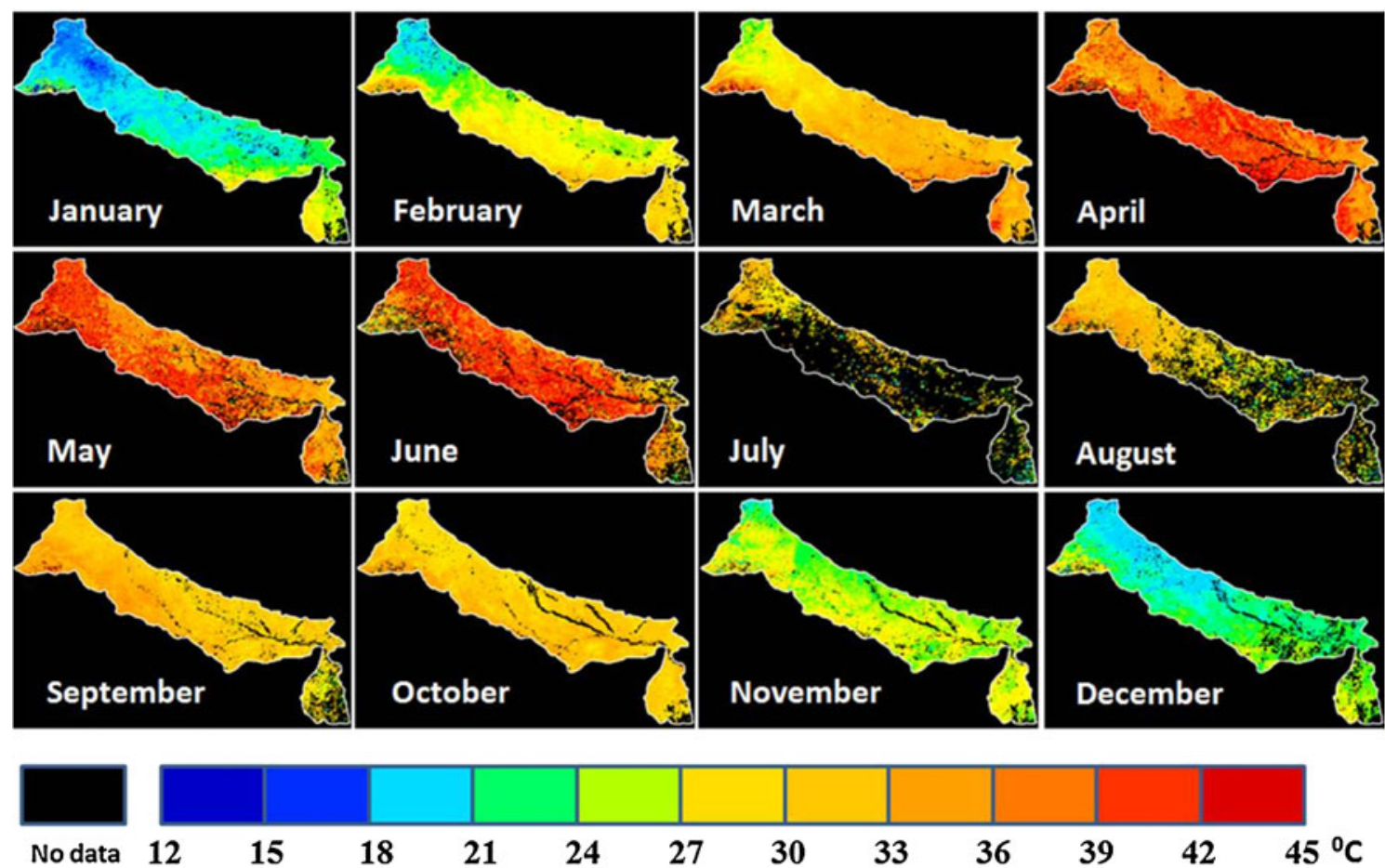

Figure 11. Spatial distribution of monthly average $T_{\max }$ images over Indo-Gangetic Plain for the year 2010.

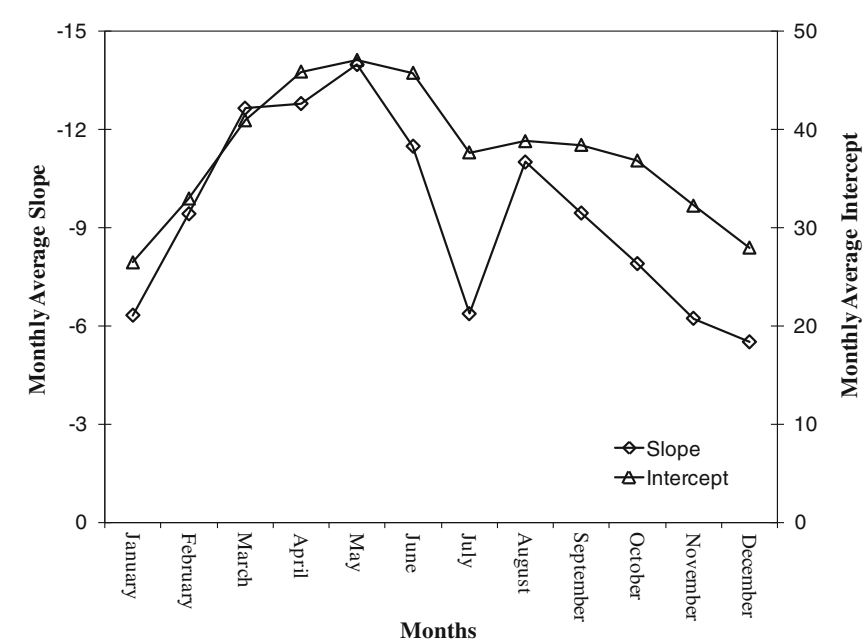

Figure 12. Monthly average variation of slope and intercept for TVX approach.

- The diurnal variation of air temperature in clear sky day shows sino-exponential pattern similar to $T_{\mathrm{s}}$ but there is the lag time between local solar noon (around 13:30 IST) and $T_{\max }$ occurrence (around 16:00 IST). MODIS Aqua passes around 13:30 IST which is the time for occurrences of maximum $T_{\mathrm{s}}$ but $T_{\max }$ takes place around 16:00 IST over the IGP. Hence, variation of satellite overpasses time over IGP introduces errors for $T_{\max }$ estimation.

\section{Conclusions}

A study was carried out to estimate $T_{\min }$ and $T_{\max }$ over the IGP using MODIS $T_{\mathrm{s}}$ and IMD measured $T_{\min }$ and $T_{\max }$ observation from 19 stations. From the statistical analysis between night time MODIS Aqua $T_{\mathrm{s}}$ and IMD $T_{\min }$ measured at 19 stations represented a good agreement with the MAE of $1.73^{\circ} \mathrm{C}$ and RMSE of $2.2^{\circ} \mathrm{C}$. Hence, MODIS Aqua $T_{\mathrm{s}}$ products were found to be accurate enough to spatially represent $T_{\min }$ in an operational way with an 8-day frequency. A methodology of computing $\mathrm{NDVI}_{\max }$ was developed to estimate $T_{\max }$ using the TVX approach. The results showed similar performances compared to previous studies with the MAE of $1.79^{\circ} \mathrm{C}$ and RMSE of $2.16^{\circ} \mathrm{C}$. This work confirms that 8-day average $T_{\min }$ and $T_{\max }$ can be accurately estimated using MODIS products which can be useful in applications such as vegetation water status availability, evapotranspiration and high temperature extremes related with the urban heat island effect. This study was carried out using 8-day composite MODIS data but one can use similar approach for daily dataset for real-time application to the models. This kind of methods will be very useful in the INSAT-3D satellite time frame where diurnal estimates of LST will be available over India. 


\section{Acknowledgements}

This work has been carried out in a collaborative study under INSAT-3D utilization program. The authors thank Shri A S Kirankumar, Director, SAC, Dr J S Parihar, Deputy Director, EPSA, Dr B Bakshi, Principal, NVPAS, for their guidance and support to the study. They acknowledge Ms. Radhika Chipade for her help in implementing TVX approach on satellite images. They also acknowledge the MODIS mission scientist and NASA personal for the production of the data used in this study and IMD measured data provider team. The authors wish to thank the reviewers for their valuable contribution and comments to this work.

\section{References}

Bayarjargal Y, Karnieli A, Bayasgalan M, Khudulmur S, Gandush C and Tucker C J 2006 A comparative study of NOAA-AVHRR derived drought indices using change vector analysis; Remote Sens. Environ. 105 $9-22$.

Bhowmick S A, Mallick K, Bhattacharya B K and Nigam R 2008 Retrieval of air temperature in clear skies using Indian geostationary satellite data; J. Agrometeorol. 2 $545-556$.

Boegh E, Soegaard H, Hanan N, Kabat P and Lesch L 1999 A remote sensing study of the NDVT- $T_{\mathrm{S}}$ relationship and the transpiration from sparse vegetation in the Sahel based on high-resolution satellite data; Remote Sens. Environ. 69 224-240.

Cresswell M P, Morse A P, Thomson M C and Connor S J 1999 Estimating surface air temperatures, from Meteosat land surface temperatures, using an empirical solar zenith angle model; Int. J. Remote Sens. 20 1125-1132.

Czajkowski K P, Goward S N, Stadler S J and Walz A 2000 Thermal remote sensing of near surface environmental variables: Application over the Oklahoma Mesonet; Prof. Geogra. 52 345-357.

Czajkowski K P, Mulhern T, Goward S N, Cihlar J, Dubayah R O and Prince S D 1997 Biospheric environmental monitoring at BOREAS with AVHRR observations; J. Geophys. Res. (Atmospheres) 102 29,651-29,662.

Davis F A and Tarpley J D 1983 Estimation of shelter temperatures from operational satellite sounder data; J. Appl. Meteorol. 22 369-376.

Florio E N, Lele S R, Chang Y C, Sterner R and Glass G E 2004 Integrating AVHRR satellite data and NOAA ground observations to predict surface air temperature: A statistical approach; Int. J. Remote Sens. 25 2979-2994.

Goward S N, Cruickshanks G D and Hope A S 1985 Observed relation between thermal emission and reflected spectral radiance of a complex vegetated landscape; Remote Sens. Environ. 18 137-146.

Goward S N, Waring R H, Dye D G and Yang J L 1994 Ecological remote-sensing at OTTER-Satellite macroscale observations; Ecol. Appl. 4 322-343.

Goward S N, Xue Y and Czajkowski K P 2002 Evaluating land surface moisture conditions from the remotely sensed temperature-vegetation index measurements: An exploration with the simplified simple biosphere model; Remote Sens. Environ. 79 225-242.
Jang J D, Viau A A and Anctil F 2004 Neural network estimation of air temperatures from AVHRR data; Int. J. Remote Sens. 25 4541-4554.

Lakshmi V, Czajkowski K, Dubayah R and Susskind J 2001 Land surface air temperature mapping using TOVS and AVHRR; Int. J. Remote Sens. 22 643-662.

Nemani R R and Running J W 1989 Estimation of regional surface resistance to evapotranspiration from NDVI and thermal-IR AVHRR data; J. Appl. Meteorol. 28 $276-284$.

Nieto H, Aguado I, Chuvieco E and Sandholt I 2010 Dead fuel moisture estimation with MSG-SEVIRI data. Retrieval of meteorological data for the calculation of the equilibrium moisture content; Agri. Forest Meteorol. 150 861-870.

Oke T R 1987 Boundary Layer Climates; 2nd edn, Routledge, London, 435p.

Olioso A, Chauki H, Courault D and Wigneron J P 1999 Estimation of evapotranspiration and photosynthesis by assimilation of remote sensing data into SVAT models; Remote Sens. Environ. 68 341-356.

Pineiro G, Perelman S, Guerschman J P and Paruelo J M 2008 How to evaluate models: Observed vs. predicted or predicted vs. observed?; Ecol. Modelling 216 316-322.

Price J C 1990 Using spatial context in satellite data to infer regional scale evapotranspiration; IEEE Trans. Geosci. Remote Sens. 28 940-948.

Prihodko L and Goward S N 1997 Estimation of air temperature from remotely sensed surface observations; Remote Sens. Environ. $60335-346$.

Prince S D, Goetz S J, Dubayah R O, Czajkowski K P and Thawley M 1998 Inference of surface and air temperature, atmospheric precipitable water and vapor pressure deficit using Advanced Very High-Resolution Radiometer satellite observations: Comparison with field observations; J. Hydrol. 213 230-249.

Shah D B, Pandya M R, Trivedi H J and Jani A R 2012 Estimation of minimum and maximum air temperature using MODIS data over Gujarat; J. Agrometeorol. 14(2) 111-118.

Stisen S, Sandholt I, Norgaard A, Fensholt R and Eklundh L 2007 Estimation of diurnal air temperature using MSG SEVIRI data in West Africa; Remote Sens. Environ. 110 262-274.

Stisen S, Jensen K H, Sandholt I and Grimes D I F 2008 A remote sensing driven distributed hydrological model of the Senegal River basin; J. Hydrol. 354 131-148.

Sun Y J, Wang J F, Zhang R H, Gillies R R, Xue Y and Bo Y C 2005 Air temperature retrieval from remote sensing data based on thermodynamics; Theor. Appl. Climatol. $8037-48$.

Vancutsem C, Ceccato P, Dinku T and Connor S J 2010 Evaluation of MODIS land surface temperature data to estimate air temperature in different ecosystems over Africa; Remote Sens. Environ. 114 449-465.

Vogt J V, Viau A A and Paquet F 1997 Mapping regional air temperature fields using satellite-derived surface skin temperatures; Int. J. Climatol. 17 1559-1579.

Willmott C J, Robeson S M and Feddema J J 1991 Influence of spatially-variable instrument networks on climatic averages; Geophys. Res. Lett. 18 2249-2251.

Wan Z and Dozier J 1996 A generalised split-window algorithm for retrieving land surface temperature from space; IEEE Trans. Geosci. Remote Sens. 34 892-905.

Wan Z and Li Z L 2008 Radiance-based validation of the V5 MODIS land-surface temperature product; Int. J. Remote Sens. 29 5373-5395. 
Wloczyk C, Borg E, Richter R and Miegel K 2011 Estimation of instantaneous air temperature above vegetation and soil surfaces from Landsat 7 ETM+ data in northern Germany; Int. J. Remote Sens. 32 9119-9136.

Zaksek K and Schroedter-Homscheidt M 2009 Parameterization of air temperature in high temporal and spatial resolution from a combination of the SEVIRI and MODIS instruments; ISPRS J. Photogram. Remote Sens. 64 $414-421$.

Zhang W, Huang Y, Yu Y and Sun W 2010 Empirical model for estimating daily maximum, minimum and mean air temperature with MODIS land surface temperatures; Int. J. Remote Sens. 32 9415-9440.

MS received 14 October 2012; revised 1 May 2013; accepted 5 May 2013 